\title{
EDITORIAL
}

La Facultad de Medicina de la Pontificia Universidad Javeriana no sería lo que es sin la existencia del Hospital Universitario de San Ignacio (HUSI), la revista Universitas Médica, como órgano oficial de difusión de la Facultad rinde homenaje al HUSI en su cumpleaños número setenta, y para ello reproducimos las palabras del Dr. Julio César Castellanos R., su director general, pronunciadas en la solemne ceremonia celebrada el 19 de octubre del 2012.

Luis Fernando Jaramillo G., MD, MSc.

Editor

\section{Setenta años del nacimiento de un reto: el HUSI}

La consolidación de las instituciones sin ánimo de lucro en Colombia, que prestan servicios de salud a las personas menos favorecidas, ha sido un proceso lleno de obstáculos que solo quienes tienen capacidad visionaria y liderazgo asumen como un reto, y este ha sido el camino que nuestro Hospital ha recorrido durante estos setenta años.

El mayor de los peligros cuando se emprende una obra no es que nuestro objetivo sea demasiado alto y no lo alcancemos, sino que sea demasiado bajo y lo logremos, por cuanto las metas de fácil logro no requieren grandes empeños. Como se define en el Diccionario de la Real Academia Española, reto es un objetivo o empeño difícil de llevar a cabo y que constituye, por ello, un estímulo y un desafío para quien lo afronta.

Grandes hombres y mujeres se han consagrado a tareas inspiradoras, que incluso en algunos casos les ha implicado menciones destacadas en la historia, y en nuestro caso, es ejemplo de ello el padre Félix Restrepo, S. J., de quien Ignacio Chávez, director del Instituto Caro y Cuervo, afirmó en 1999: 
Ilustre sacerdote antioqueño, fundador del Instituto Caro y Cuervo, rector de la Pontificia Universidad Javeriana y renovador de la Academia Colombiana de la Lengua, fue dueño de una recia personalidad, polifacética y de gran significación tanto en nuestra patria como en otros países de la hispanidad, ejemplo de apóstoles, educadores y humanistas. El padre Félix fue un filólogo destacado y pensador desvelado por el destino de nuestro pueblo, por la defensa y proyección de nuestro patrimonio cultural en especial, la lengua que unifica y aglutina a cientos de miles de hispanohablantes y que define su destino histórico y por la restauración del prestigio intelectual de nuestra patria.

Este dilecto hombre de letras asumió en su rectoría de la Universidad Javeriana retos específicos a nuestro quehacer, como la creación de la Facultad de Medicina de la Pontificia Universidad Javeriana y, en su tiempo, del Hospital de San Ignacio.

El reverendo padre Félix Restrepo, S. J., rector de la Pontificia Universidad Javeriana, inició la fundación del Hospital como entidad pública, que se consolida naciendo como persona jurídica de derecho canónico mediante el Decreto 22 que firmó el arzobispo primado Luis Andrade Valderrama, el $1^{\circ}$ de abril de 1942. Posteriormente se le reconoció la personería jurídica mediante Resolución 81 de 1942, emanada por el Ministerio de Gobierno. En 1970, el Hospital recibe el nombre de Hospital Universitario de San Ignacio, y se aprobó la reforma estatutaria con la Resolución 1038 del 8 de febrero de 1988, emanada por el Ministerio de Salud.

De esas reuniones y acciones iniciales se originó un proyecto que buscaba tener al servicio de la ciudad 640 camas proyectadas — meta aún no cumplida—, en tres grupos de servicios: los llamados pabellones de caridad (adultos y pediátrico), el del clero y el de pensionados. Por las dificultades del proceso de construcción y dotación se avanza lentamente, y así es como, catorce años después, en 1956, se abre el servicio de consulta externa, y en tres años más, en 1959, se inicia la hospitalización en el servicio de ginecobstetricia.

Durante la evolución en estos setenta años es necesario tener presentes los profundos cambios sociales y económicos que se dan en el sistema hospitalario y de salud. El Hospital que se forjó en 1942 se creó como respuesta a una necesidad frente a la carencia de instituciones de este tipo, una época en que los hospitales públicos eran pocos, limitados y la atención hospitalaria recaía principalmente en unas instituciones dedicadas a atender a las personas con recursos económicos, que se denominaban 
"clínicas", y los hospitales de "caridad", instituciones privadas tipo fundación, generalmente creadas o regentadas por comunidades religiosas que atendían al resto de la población y que se financiaban con donaciones, transferencias económicas del gobierno y las cuotas de recuperación que los pacientes pagaban de acuerdo con una clasificación socioeconómica que hacían los hospitales mismos.

En estos años, el país pasó por un seguro social para trabajadores, las pólizas de seguro y los modelos de prepago para llegar al sistema vigente hoy de seguridad social en salud. Hoy, el Sistema de Salud y, principalmente, las normas administrativas exigen sólidos procesos económicos y financieros que, en razón a las premuras económicas, en ocasiones, alejan las prioridades institucionales de su razón de ser: la atención médica. Además, los nuevos retos que deben superar los científicos, como la búsqueda de nuevos tratamientos y la comprensión de nuevas enfermedades y su manera de tratarlas, ejemplifican una de las tareas a las que se debe enfrentar el hospital contemporáneo.

Deseo resaltar, de manera comparativa, el objeto social que los primeros estatutos del HUSI contuvieron: "Ejercitar la caridad cristiana, prestando atención médica gratuita a los pobres que de todos los departamentos del país acuden a la capital, y servir de campo de estudio, práctica e investigación a profesores y estudiantes de la Universidad Javeriana". El que evolucionó al contenido de los estatutos vigentes:

La prestación de servicios integrales de salud a la sociedad, inspirado en los principios de fraternidad y solidaridad cristiana, en la medida de sus recursos y posibilidades, sirviendo de campo de estudio, práctica e investigación, preferencialmente, a los profesores y estudiantes de la Pontificia Universidad Javeriana. También podrá prestar sus servicios a otras instituciones de educación superior del país o del extranjero debidamente autorizadas. En razón de los servicios integrales de salud que debe prestar el Hospital, se brindará atención espiritual y sacramental tanto a los enfermos y a sus familiares como a tocas las personas que laboran en el Hospital, y se procurará el cultivo de su vivencia cristiana.

Fuimos y somos una entidad confesionalmente cristiana que se compromete a respetar los valores de quienes en ella trabajan y a quienes ella sirve, con la profunda convicción de que como iguales y semejantes al Señor, tenemos la misma e igual dignidad y lo que nos engrandece es el amor por los demás, manifestado como un servicio cálido y oportuno al que lo necesita. 
Por ello, y siguiendo lo que nuestro patrono Ignacio de Loyola nos enseñó en sus ejercicios espirituales numeral 233, los invito a que los creyentes pidamos al Señor conocimiento interno de tanto bien recibido, para que enteramente, entendiéndonos, podamos en todo amar y servir.

El amor y servicio que todos brindamos a nuestros pacientes recibe el soporte y apoyo de otras personas, quienes convencidas de que es importante dar y ayudar como testimonio de caridad —y por ello es necesario destacar en esta ocasión-, a riesgo de omitir alguno, menciono a quienes las notas históricas y el pasado reciente destacan como benefactores de esta obra: don Julio Ramírez Johns, durante su vida y el legado póstumo que nos dejó con su Fundación Julio Ramírez Johns y en la empresa John Ram S. A.; a don Ernesto Castellanos y su Fundación; a la señora Mercedes Sierra de Pérez; la señora Alejandrina Gutiérrez, viuda de Cuervo; la señora Magdalena Muñoz, viuda de Carrizosa, más tarde religiosa de la Visitación de Nuestra Señora; a la comunidad judía; a la Fundación Morris Gutt Pro Infancia; a Felipe Echavarría Olózaga; a Misereor; a Victoria \& Alberto Gildred Foundation; a Muebles Artecto; a la Familia Haime; a la Fundación Luis Carlos Sarmiento Angulo, y a nuestro muy querido amigo, paciente y consejero don Arturo Calle Calle.

Debo presentar un reconocimiento de homenaje póstumo al padre Gerardo Arango Puerta, quien entre 1986 y 1989 dirigió el Hospital y logró consolidarlo en otra de sus grandes crisis del pasado.

La historia vivida y las necesidades del país nos ponen un nuevo reto, que consiste en estar a la vanguardia en tecnología e innovación en el área de la salud y ser una institución de alta complejidad, lo cual significa que los pacientes de todos los estratos que recurren a nosotros tienen acceso a instrumentos o equipos (tecnología dura) con el mejor conocimiento (tecnología blanda) para la valoración y tratamiento de sus enfermedades o dolencia. En síntesis, como centro de alta complejidad, somos una entidad en la cual hay la mayor cantidad de maestros de la medicina clínica que ejercen activamente para orientar de manera racional, sistemática y altamente benéfica los planes de tratamiento, que contemplarán incluso los más avanzados desarrollos de la medicina instrumentada. Con el compromiso adicional, que esos maestros transmitan esa experticia a los profesionales en formación. Todo ello para ofrecer un tratamiento adecuado y más humano a los que lo necesiten.

Preparando este texto reflexionaba sobre qué tanto honor hemos hecho al espíritu de los fundadores, y aunque creo que falta más, ofrece en parte satisfacción del deber 
cumplido el verificar que hoy en nuestro Hospital, entre los cientos de pacientes, hay el día que se escribe cinco personas víctimas de la violencia provenientes de zonas rurales de Norte de Santander, Arauca y Meta, a quienes pudimos acoger para atender cuando las autoridades de salud y el Comité Internacional de la Cruz Roja no encontraban cupo o disponibilidad en otras entidades de alta complejidad. Si bien la mayoría de instituciones estamos en sobreocupación, por el manejo de las urgencias habituales, nuestros procesos nos permiten generar espacios para brindar a estos pacientes la atención que sus heridas requieren.

La conmemoración más hermosa es aquella en la que se manifiesta la gratitud a quienes sirven y han servido a las ideas, más cuando ellas se expresan en el servicio. Por ello, como noveno director del Hospital, desde que en 1966 se independizó la administración de la de la Universidad, muchas gracias a todos y todas quienes han contribuido en estos setenta años a consolidar este Hospital. Al Creador le pedimos que nos acompañe con su Luz, a los que hoy estamos y a quienes vendrán, para mantener procesos sostenibles que permitan seguir atendiendo a los pacientes que las demás instituciones no pueden o quieren recibir por complejos, pobres o marginados. Todo ello nos implica colocar el poder del conocimiento médico y de enfermería al servicio de muchos, en especial de los más vulnerables, haciendo realidad nuestro lema "Ciencia y Tecnología con Proyección Social".

Julio César Castellanos Ramírez, MD

Director general

Hospital Universitario de San Ignacio 